\title{
Hepatic infarction: an unusual complication of nephrotic syndrome in a patient with diabetes mellitus
}

\author{
Alberto Martinez Vea, Carmen Garcia Ruiz, Amadeo Sauri Conejero', Emilio \\ Mayayo Artal' ${ }^{2}$ and Jesus A. Oliver Rotellar
}

Service of Nephrology, 'Department of Radiology and ${ }^{2}$ Department of Pathology, Hospital Joan XXIII, 43007 Tarragona, Spain

\begin{abstract}
Summary: A 67 year old woman with widespread atherosclerosis and diabetic nephropathy manifested by nephrotic syndrome and moderate renal failure developed multiple hepatic infarctions. The infarctions were documented by computed tomographic scan and needle aspiration biopsy of the liver. Except for the nephrotic syndrome and the atherosclerosis no other cause of hepatic infarction was found.

We suggest that hepatic infaretion should be considered in the thrombotic complications of the nephrotic syndrome secondary to diabetic nephropathy.
\end{abstract}

\section{Introduction}

Thromboembolism is a common complication of the nephrotic syndrome, due to the hypercoagulable state present in nephrotic patients. ${ }^{1-3}$ The commonest sites of thrombosis are the veins, renal, deep leg and pulmonary being the most affected veins. ${ }^{1-3}$ Thrombotic complications can also involve major arteries, including pulmonary, axillary, subclavian, brachial, renal, aortic, femoral, iliac, popliteal, coronary, ophthalmic, carotid and cerebral arteries. ${ }^{4-6}$ Aortic, femoral and renal arteries are the most commonly involved vessels in adult nephrotic patients, whereas femoral and pulmonary arteries are the commonest ones in nephrotic children. ${ }^{4-6}$

We would like to report a case of multiple hepatic infarctions in a diabetic patient with nephrotic syndrome. To our knowledge, this thrombotic complication has not been reported in the nephrotic syndrome secondary to diabetic nephropathy.

\section{Case report}

A 67 year old woman was admitted to the hospital because of unstable angina pectoris and heart failure. There was a 20-year history of diabetes mellitus that was complicated by diabetic retinopathy, angina pectoris, arterial hypertension and severe peripheral vascular disease. Diabetic nephropathy manifested by nephrotic syndrome and moderate renal failure was evident one year before.

Correspondence: A. Martinez Vea, M.D.

Accepted: 25 April 1990
On admission the patient had clinical and radiological signs of congestive heart failure. The pulse was 80 beats per minute and the blood pressure was $140 / 80 \mathrm{mmHg}$. An electrocardiogram showed anterior and lateral myocardial ischaemia.

Laboratory investigations showed: haemoglobin $8.4 \mathrm{~g} / \mathrm{dl}$, white cell count $7.6 \times 10^{9} / 1$, erythrocyte sedimentation rate $93 \mathrm{~mm} / \mathrm{h}$; glucose $13.4 \mathrm{mmol} / \mathrm{l}$, urea $27 \mathrm{mmol} / \mathrm{l}$, creatinine $243 \mu \mathrm{mol} / \mathrm{l}$, albumin $25.3 \mathrm{~g} / \mathrm{l}$, globulins $23.7 \mathrm{~g} / \mathrm{l}$, total cholesterol $9.2 \mathrm{mmol} / \mathrm{l}$, triglycerides $2.2 \mathrm{mmol} / \mathrm{l}$. In a 24 -hour specimen of urine the protein was $6 \mathrm{~g}$. Coagulation studies and liver function tests were normal.

Treatment was instituted with high dose of frusemide, nitroglycerin patches, nifedipine, captopril and insulin. A diuresis occurred and the signs of cardiac failure improved.

On the tenth hospital day, when the patient was stable, she developed a sudden midepigastric pain with intense diaphoresis. The blood pressure was $200 / 80 \mathrm{mmHg}$, the pulse 72 beats per minute and the temperature $36^{\circ} \mathrm{C}$. Abdominal examination revealed tenderness in the upper abdomen with abdominal distension and diminished bowel sounds. Pain persisted for 24 hours requiring morphine treatment. Plain abdominal film showed increased small and large bowel gas. A gastrointestinal endoscopy was normal. The electrocardiogram did not change. The glucose was $6.5 \mathrm{mmol} / \mathrm{l}$, the creatine kinase $37 \mathrm{U}$, the amylase $174 \mathrm{U} / 1$, the SGOT $1335 \mathrm{U} / 1$ (normal $41 \mathrm{U} / \mathrm{l}$ ), the SGPT $2310 \mathrm{U} / \mathrm{l}$ (normal $45 \mathrm{U} / \mathrm{l}$ ), the lactic dehydrogenase $675 \mathrm{U} / 1$, the alkaline phosphatase $321 \mathrm{U} / 1$ and the gamma-glutamyltransferase 90 $\mathrm{U} / \mathrm{l}$. The total bilirubin, the platelet count, the 
prothrombin time, the partial thromboplastin time and the fibrinogen level were all normal.

An abdominal ultrasonography demonstrated multiple hepatic echogenic lesions; the portal vein was normal and ascites was not evident. An abdominal computed tomographic scan (Figure 1) showed multiple well-defined nonenhancing filling defects involving right and left hepatic lobes, suggesting liver infarctions. ${ }^{7,8} \mathrm{~A}$ fine needle aspiration biopsy of the liver with computed tomographic (CT) guidance revealed extent necrotic areas with some leucocytic infiltrate (Figure 2). The diagnosis of multiple hepatic infarction was established.

The patient was maintained on her habitual therapy. Over the next several days, she improved clinically and chemically. Liver function tests became normal in the ensuing month. A repeated computed tomographic scan performed two months later was normal.

\section{Discussion}

Hepatic infarction is an unusual event probably because of the extensive hepatic arterial collateral system $^{9,10}$ and the liver dual blood supply from the portal vein and hepatic arteries. ${ }^{11}$ Under normal conditions, the hepatic artery supplies about $35 \%$ of hepatic blood flow and $50 \%$ of the oxygen required by the liver, while the portal vein supplies the remainder. ${ }^{11}$

Hepatic infarction with ischaemic necrosis usually occurs when the hepatic artery or its branches are occluded or when the portal vein is thrombosed. ${ }^{12}$ In addition, hepatic infarction without any demonstrable vascular occlusion has been reported in the setting of shock, sepsis, anaesthesia, biliary disease and diabetic ketoacidosis. ${ }^{12-16}$ In our case, clinical features of portal hypertension were not present and the abdominal ultrasound did not demonstrate that the portal vein was thrombosed. Furthermore, no shock, sepsis or diabetic ketoacidosis were evident in our patient.

Common causes of hepatic artery occlusion include polyarteritis nodosa, septic emboli, hepatic artery catheterization for chemotherapeutic infusions, inadvertent ligation of the hepatic artery, hepatic artery thrombosis associated with oral contraceptive use or with neoplasms of the liver or bile ducts, and atherosclerosis. ${ }^{13-20}$ Except for the latter, none of the other causes was apparent in out patient.

Arterio- and arteriolosclerosis of intrahepatic branches are commonly seen in hypertensive patients, causing thickening of the media of the small arteries in the portal tracts. ${ }^{12}$ In fact, hepatic artery thrombosis has been reported in patients with generalized atherosclerosis, ${ }^{13,21}$ sometimes associated with thrombosis of the coeliac trunk $;^{21}$ case

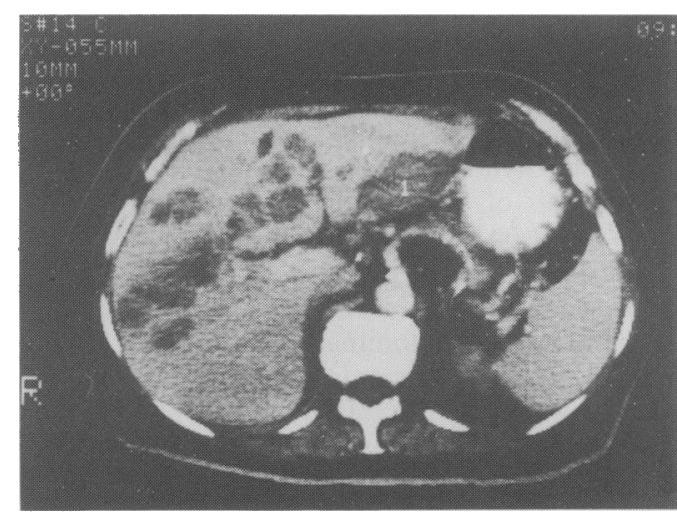

Figure 1 Abdominal computed tomographic scan showing multiple nonenhancing filling defects of liver.

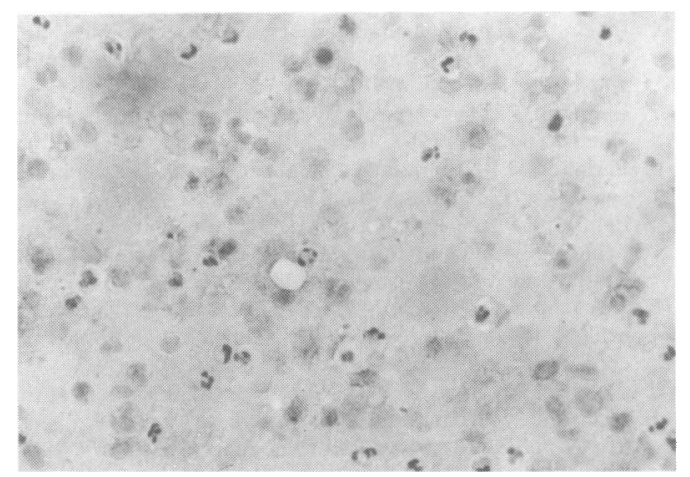

Figure 2 Needle aspiration biopsy of the liver showing necrotic background with some leucocytic infiltrate and cellular debris (Papanicolaou $\times 212$ ).

reports of cholesterol emboli producing liver infarction have also been described..$^{22,23}$ Our patient had a complicated diabetes with hypertension and widespread atherosclerosis; these factors could probably contribute to the hepatic infarction, although diabetes itself could contribute to this. Thus, abnormalities of platelet aggregation, ${ }^{24}$ plasma viscosity ${ }^{25}$ and fibrinolysis ${ }^{26}$ tending to increased thrombosis and decreased fibrinolysis have been found in diabetic patients with angiopathy.

In addition to diabetes and atherosclerosis, one important factor that probably contributed to the hepatic infarction in this case was the nephrotic syndrome. A hypercoagulable state and thromboembolic complications are well-known features of nephrotic syndrome in adults. ${ }^{1-3}$ Venous thrombosis is the current pattern of thrombosis in adult nephrotic patients, whereas arterial thrombosis is much less common. ${ }^{1-3}$ This is the opposite of nephrotic children in whom there is a much lower overall incidence of thrombosis, but half of the 
reported thrombotic complications involved arterial vessels. ${ }^{4,6}$

Although many major arteries have been involved in the thrombotic complications of the nephrotic syndrome, hepatic infarction due to thrombosis of the hepatic artery or its branches have not been reported. In Sullivan's, ${ }^{5}$ Egli' ${ }^{4}$ and Cameron's ${ }^{6}$ extensive reviews of paediatric and adult nephrotic patients with arterial or venous thrombosis, intrabdominal vessels such as mesenteric, spleen, or portal veins, and mesenteric arteries were rarely involved, and no patient had a hepatic artery thrombosis. Thus, hepatic infarction as a complication of nephrotic syndrome secondary to diabetic nephropathy is an exceptional

\section{References}

1. Llach, F. Hypercoagulability, renal vein thrombosis and other thrombotic complications of nephrotic syndrome. Kidney Int 1985, 28: 429-439.

2. Cameron, J.S. The nephrotic syndrome and its complications. Am J Kidney Dis 1987, 10: 157-171.

3. Bernard, D.B. Extrarenal complications of the nephrotic syndrome. Kidney Int 1988, 33: 1184-1202.

4. Egli, F., Eimiger, P. \& Stalder, G. Thromboembolism in the nephrotic syndrome. European Society of Paediatric Nephrology (abstr 42). Pediatr Res 1974, 8: 903.

5. Sullivan, M.J., Hough, D.R. \& Agodoa, L.C.Y. Peripheral arterial thrombosis due to the nephrotic syndrome: the clinical spectrum. South Med J 1983, 76: 1011-1016.

6. Cameron, J.S., Ogg, Ch.S. \& Wass, V.J. Complications of the nephrotic syndrome. In: Cameron, J.S., Glassock, R.J. (eds) The Nephrotic Syndrome. Marcel Dekker, New York, 1988, pp. 849-920.

7. Adler, D.D., Glazer, G.M. \& Silver, T.M. Computed tomography of liver infarction. AJR 1984, 142: 315-318.

8. Lev-Toaff, A.S., Friedman, A.C., Cohen, L.M., Radecki, P.D. \& Caroline, D.F. Hepatic infarcts: new observation by CT and sonography. AJR 1987, 149: 87-90.

9. Michels, N.A. Newer anatomy of liver-variant blood supply and collateral circulation. JAMA 1960, 172: 125-132.

10. Mays, E.T. \& Wheeler, C.S. Demonstration of collateral arterial flow after interruption of hepatic arteries in man. $N$ Engl J Med 1974, 290: 993-996.

11. Tygstrup, N., Winkler, K., Mellemgaard, K. et al. Determination of the hepatic arterial blood flow and oxygen supply in man by clamping the hepatic artery during surgery. $J$ Clin Invest 1962, 41: 447-454.

12. Bras, G. \& Brandt, K.H. Vascular disorders. In: MacSween R.N.M., Anthony, P.P., Schever, P.J. (eds) Pathology of the Liver. Churchill Livingstone, Edinburgh, 1987, pp. 478-502.

13. Seeley, T.T., Blumenfeld, C.M., Ikeda, R. et al. Hepatic infarction. Hum Pathol 1972, 3: 265-276. finding. Furthermore, it is remarkable that this glomerulopathy, for reasons that are not understood, does not carry a high risk of arterial or venous thrombotic complications, in contrast to other glomerulopathies, such as membranous and mesangiocapillary glomerulonephritis, lupus nephritis and amyloidosis, in which there is a high incidence of thrombosis. ${ }^{6}$

In summary, except for the atherosclerosis and nephrotic syndrome, no other possible cause of hepatic infarction was found in our case. We suggest that liver infarction should be considered in the thrombotic complications of the nephrotic syndrome secondary to diabetic nephropathy.

14. Kanter, D.M. Hepatic infarction. Arch Intern Med 1965, 115: 479-481.

15. Chen, V., Hamilton, J. \& Qizilbash, A. Hepatic infarction: a clinicopathologic study of seven cases. Arch Pathol Lab Med 1976, 100: $32-36$.

16. Ng, R.C.K., Sigmund, Ch.J., Lagos, J.A. \& Chernin, M. Hepatic infarction and diabetic ketoacidosis. Gastroenterology 1977, 73: 804-807.

17. Kim, D.K., Kenne, D.W. \& Fortner, J.D. Occlusion of the hepatic artery in man. Surg Gynecol Obstet 1973, 136: 966-969.

18. Lucas, R.J., Tumacder, O. \& Wilson, G.S. Hepatic artery occlusion following hepatic artery catheterization. Ann Surg 1971, 173: 238-243.

19. Carrol, R. Infarction of the human liver. J Clin Pathol 1963, 16: $133-136$.

20. Jacobs, M.B. Hepatic infarction related to oral contraceptive use. Arch Intern Med 1984, 144: 642-643.

21. O'Connor, P.J., Buhac, I. \& Balint, J.A. Spontaneous hepatic artery thrombosis with infarction of the liver. Gastroenterology 1976, 70: 599-601.

22. Castleman, B., Skully, R.E. \& McNeeley, B.U. Case records of the Massachusetts General Hospital-weekly clinicopathological exercises. N Engl J Med 1972, 286: $1146-1153$.

23. Castleman, B., Skully, R.E. \& McNeeley, B.U. Case records of the Massachusetts General Hospital-weekly clinicopathological exercises. N Engl J Med 1973, 289: 1360-1366.

24. Colwell, J.A., Halushka, P.V., Sarji, K. et al. Altered platelet function in diabetes mellitus. Diabetes 1976, 25 (Suppl 2): 826-831.

25. McMillan, D.E. Plasma protein changes, blood viscosity and diabetic microangiopathy. Diabetes 1976, 25 (Suppl 2): 858-864.

26. Almer, L. \& Nilsson, I.M. On fibrinolysis in diabetes mellitus. Acta Med Scand 1975, 198: $101-106$. 